\title{
Novas espécies neotropicais de Acanthocinini (Coleoptera, Cerambycidae)
}

\author{
Miguel A. Monné ${ }^{1,2}$ \& Marcela L. Monné ${ }^{1}$ \\ ${ }^{1}$ Museu Nacional, Universidade Federal do Rio de Janeiro. Quinta da Boa Vista, São Cristovão, 20940-040 Rio de Janeiro, \\ Rio de Janeiro, Brasil. \\ ${ }^{2}$ Bolsista do CNPq.
}

\begin{abstract}
New species of Neotropical Acanthocinini (Coleoptera, Cerambycidae). Six new species of Acanthocinini are described: Alcidion inornatum sp. nov. from Colombia, Baryssinus giesberti sp. nov. from Panama, and four from Brazil, Baryssinus mimus sp. nov. (Rio de Janeiro), Carphina melanura sp. nov. (Mato Grosso), Lophopoenopsis albosparsus sp. nov. (Bahia, Espírito Santo) and Pseudolepturges caesius sp. nov. (Rondônia, Pará).

KEY WORDS. Lamiinae; taxonomy.
\end{abstract}

RESUMO. Seis novas espécies são descritas em Acanthocinini: Alcidion inornatum sp. nov. da Colômbia, Baryssinus giesberti sp. nov. do Panamá e quatro do Brasil, Baryssinus mimus sp. nov. (Rio de Janeiro), Carphina melanura sp. nov. (Mato Grosso), Lophopoenopsis albosparsus sp. nov. (Bahia, Espírito Santo) e Pseudolepturges caesius sp. nov. (Rondônia, Pará). PALAVRAS-CHAVE. Lamiinae; taxonomia.

O presente trabalho faz parte do estudo revisivo, realizado pelos autores, da tribo Acanthocinini, que apresenta 149 gêneros e mais de 950 espécies na Região Neotropical (Monné 2005). Seis novas espécies são descritas sendo duas em Baryssinus Bates, 1864, uma em Alcidion Sturm, 1843, uma em Carphina Bates, 1872, uma em Lophopoenopsis Melzer, 1931 e uma em Pseudolepturges Gilmour, 1957. O material examinado pertence à American Coleoptera Collection, San Antonio, Texas (ACMT), ao Museu Nacional, Universidade Federal do Rio de Janeiro, Rio de Janeiro (MNRJ) e ao National Museum of Natural History, Washington, D.C. (USNM).

\section{Alcidion inornatum sp. nov.}

Fig. 1

Fêmea. Tegumento castanho-avermelhado com pubescência acinzentada. Pubescência amarela: estreita faixa junto às margens anterior (pouco aparente) e posterior do pronoto; élitros com quatro manchas pouco aparentes, a primeira pequena, de contorno arredondado junto à sutura no final do quinto basal, a segunda transversal, parcialmente esbranquiçada, aproximada da margem no fim do quarto anterior, a terceira pequena e arredondada no meio da sutura e a quarta junto à carena dorsal no início do quarto distal.

Cabeça com raras cerdas eretas e pretas. Antenas alcançam as extremidades dos élitros no antenômero VII; com cerdas esparsas e pretas, inclusive no escapo.

Lados do protórax com tubérculo pós-mediano pequeno, com ápice direcionado para os lados. Pronoto intumescido e com fileira de pontos esparsos junto ao bordo posterior. Processo prosternal estreito, cerca de $1 / 3$ da procoxa. Processo mesosternal tão largo quanto a mesocoxa. Ápices elitrais de per si acuminados e projetados em longo espinho aguçado e com depressão aos lados da sutura. Pontuação restrita aos pontos setíferos suberetos, esparsa e não alinhada em fileiras longitudinais. Tíbias com cerdas esparsas e pretas. Protarsômero I ligeiramente mais longo que o II; meso- e metatarsômeros I $1 / 3$ mais longos que o II.

Margem apical do urotergito $\mathrm{V}$ profundamente chanfrada e com ângulos projetados em longo espinho aguçado; urosternito $\mathrm{V}$ com a margem truncada.

Dimensões, em milímetros, holótipo fêmea. Comprimento total, 8,7; comprimento do protórax, 1,3; maior largura do protórax, 2,0; comprimento do élitro, 7,0; largura umeral, 3,5.

Material-tipo. Holótipo fêmea, ColôMBIA, Cauca: Carretera Popayán-Puracé, km 15, 2200 m, 31.V.1972, C. Bordón leg. (MNRJ).

Discussão. Alcidion Sturm, 1843 apresenta atualmente 15 espécies que distribuem-se na região Neotropical (Monné 2005). Alcidion inornatum sp. nov. (Fig. 1) difere, de maneira geral, das demais espécies do gênero pelo protórax, aos lados, com tubérculo pós-mediano pouco manifesto; nas outras espécies os tubérculos são mais próximos da margem posterior e, de maneira geral, mais evidentes. Seis espécies ocorrem na região Amazônica e destas, Alcidion inornatum sp. nov. assemelha-se à $A$. chryseis (Bates, 1864), A. sulphurifer (White, 1855) e A. partitum (White, 1855) pelos ápices elitrais de per si acuminados e projetados em longo espinho aguçado e com depressão aos lados da sutura. Alcidion inornatum sp. nov. difere de A. chryseis pelo tegumento sem brilho metálico, de $A$. partitum pela presença de cerdas no escapo e de $A$. sulphurifer pelos élitros com pontos 
setíferos escassos e não alinhados. Em A. chryseis a cabeça, pronoto e élitros apresentam reflexo verde metálico, $A$. partitum não tem cerdas no escapo e os élitros em $A$. sulphurifer apresentam pontos setíferos abundantes e organizados em fileiras longitudinais.

Etimologia. Latim, inornatum = sem ornamento; referente às manchas elitrais pouco aparentes.

\section{Baryssinus giesberti sp. nov.} Fig. 2

Macho. Tegumento predominantemente castanho-claro; castanho-avermelhado nas pernas e face ventral. Pubescência de maneira geral castanho-amarelada, com brilho sedoso. Pubescência branca reveste: cabeça, pronoto (exceto manchas medianas castanho-escuras na metade posterior e máculas arredondadas da mesma cor junto às orlas anterior e posterior); nos élitros, uma curta mancha longitudinal a cada lado do escutelo e faixa larga transversal pós-mediana, com abundantes pontos setíferos ornados com pilosidade castanho-escura; metade apical do metasterno e face interna dos meso- e metafêmures.

Antenas alcançam as extremidades dos élitros no meio do antenômero VI; com raras cerdas eretas e pretas.

Lados do protórax com tubérculos com ápice voltado em direção aos úmeros. Pronoto com uma fileira de pontos grossos junto à orla posterior. Processo prosternal cerca de 1/3 da largura da procoxa; processo mesosternal com suave declive anterior e tão largo quanto a mesocoxa. Élitros com cerdas semidecumbentes; sem carena lateral pós-umeral; com pontos mais finos que os do pronoto, densos e profundos na metade basal, esparsos e rasos para os ápices; pontos setíferos parcialmente alinhados, mais densos no terço posterior. Crista centro-basal dos élitros pouco elevada, revestida de pubescência castanho-escura e setas longas e eretas; ápices elitrais arredondados. Tíbias com cerdas abundantes e pretas. Pro- e mesotarsômeros I 1/3 mais longos que o II; metatarsômero I 1,5 vezes mais longo que o II.

Urotergito e urosternito V com a margem apical truncada.

Dimensões, em milímetros, holótipo macho. Comprimento total, 9,0; comprimento do protórax, 2,0; maior largura do protórax, 3,2; comprimento do élitro, 6,8; largura umeral, 4,0.

Material-tipo. Holótipo macho, Panamá, Panamá: El LlanoCarti Rd., km 8-11, 1100', 24.V-2.VI.1992, J.E. Wappes leg. (USNM).

Discussão. Baryssinus Bates, 1864 apresenta 13 espécies que ocorrem na região Neotropical (Monné 2005). Baryssinus giesberti sp. nov. (Fig. 2) difere de B. bicirrifer Bates, 1872, B. lineaticollis (Gounelle, 1910), B. penicillatus Bates, 1864 e B. robertoi Monné \& Martins, 1976 pela ausência de carena lateral pós-umeral e das demais espécies de Baryssinus (exceto $B$. marcelae Martins \& Monné, 1974) pelo pronoto sem faixas sinuosas longitudinais de pubescência castanho-escura ou preta. O elaborado desenho elitral também permite diferenciar $B$. giesberti sp. nov. de suas congêneres, inclusive $B$. marcelae.

Etimologia. O epíteto é uma homenagem ao saudoso Edmund F. Giesbert, Los Angeles, Califórnia.

\section{Baryssinus mimus sp. nov.}

Fig. 3

Macho. Tegumento castanho-escuro a preto. A pubescência cinzento-esbranquiçada reveste a metade basal dos antenômeros III-XI, metade anterior dos élitros, pernas e face ventral. A pubescência preta recobre o occipício, o escapo, a metade distal dos antenômeros III-XI; o protórax e escutelo; nos élitros, uma estreita mancha pós-escutelar na sutura, uma pequena mancha arredondada na base, a cada lado do escutelo, na crista centrobasal e na faixa transversal em ziguezague no início do terço distal; na face ventral, recobre os epimeros, episternos e margem lateral anterior do metasterno. A pubescência amarelo-escura reveste a fronte, uma mancha pequena e arredondada a cada lado do meio do pronoto; nos élitros, mácula circumescutelar, mancha grande que limita anteriormente a pubescência preta na metade distal, e mancha grande anteapical de contornos irregulares.

Antenas alcançam as extremidades dos élitros no ápice do antenômero VII; ornadas com cerdas eretas, esparsas e pretas.

Lados do protórax com tubérculos no início do terço posterior, aguçados e com os ápices dirigidos para os úmeros; pronoto sem tubérculos e com pontuação moderadamente grossa, restrita à fileira junto à margem posterior. Processo prosternal com 1/4 da largura procoxa; processo mesosternal tão largo quanto a mesocoxa. Élitros com cerdas semidecumbentes, pretas; sem carenas; crista centro-basal formada por pêlos eretos, pretos; pontuação restrita aos pontos setíferos; ápices obliquamente subtruncados, ângulos sem espinhos. Tíbias com cerdas esparsas e pretas. Protarsômero I ligeiramente mais longo que o II; meso- e metatarsômeros I 1/3 mais longos que o II.

Urotergito e urosternito $\mathrm{V}$ truncados na margem apical.

Dimensões, em milímetros, holótipo macho. Comprimento total, 10,0; comprimento do protórax, 2,0; maior largura do protórax, 3,0; comprimento do élitro, 7,0; largura umeral, 4,0.

Material-tipo. Holótipo macho. BRASIL, Rio de Janeiro: Silva Jardim, I.1981, O. Roppa leg. (MNRJ).

Discussão. Assim como em Baryssinus giesberti sp. nov., $B$. mimus sp. nov. (Fig. 3) não apresenta carena lateral nos élitros e o pronoto não tem faixas longitudinais. A pubescência do pronoto, preta com duas pequenas manchas de pubescência amarelo-escura medianas, diferem esta das demais espécies do gênero.

Etimologia. Latim, mimus = imitador; refere-se à semelhança na coloração que $B$. mimus sp. nov. tem com espécies do gênero Eupromerella (Acanthoderini), principalmente $E$. propinqua (Melzer, 1931) e E. semigrisea (Bates, 1861).

\section{Carphina melanura sp. nov.}

Fig. 4

Fêmea. Tegumento castanho-escuro. Pubescência predominantemente acinzentada, densa. Pubescência preta aveludada recobre: mancha mediana longitudinal, com as margens laterais arredondadas, no pronoto, lados do escutelo e, em cada élitro, 

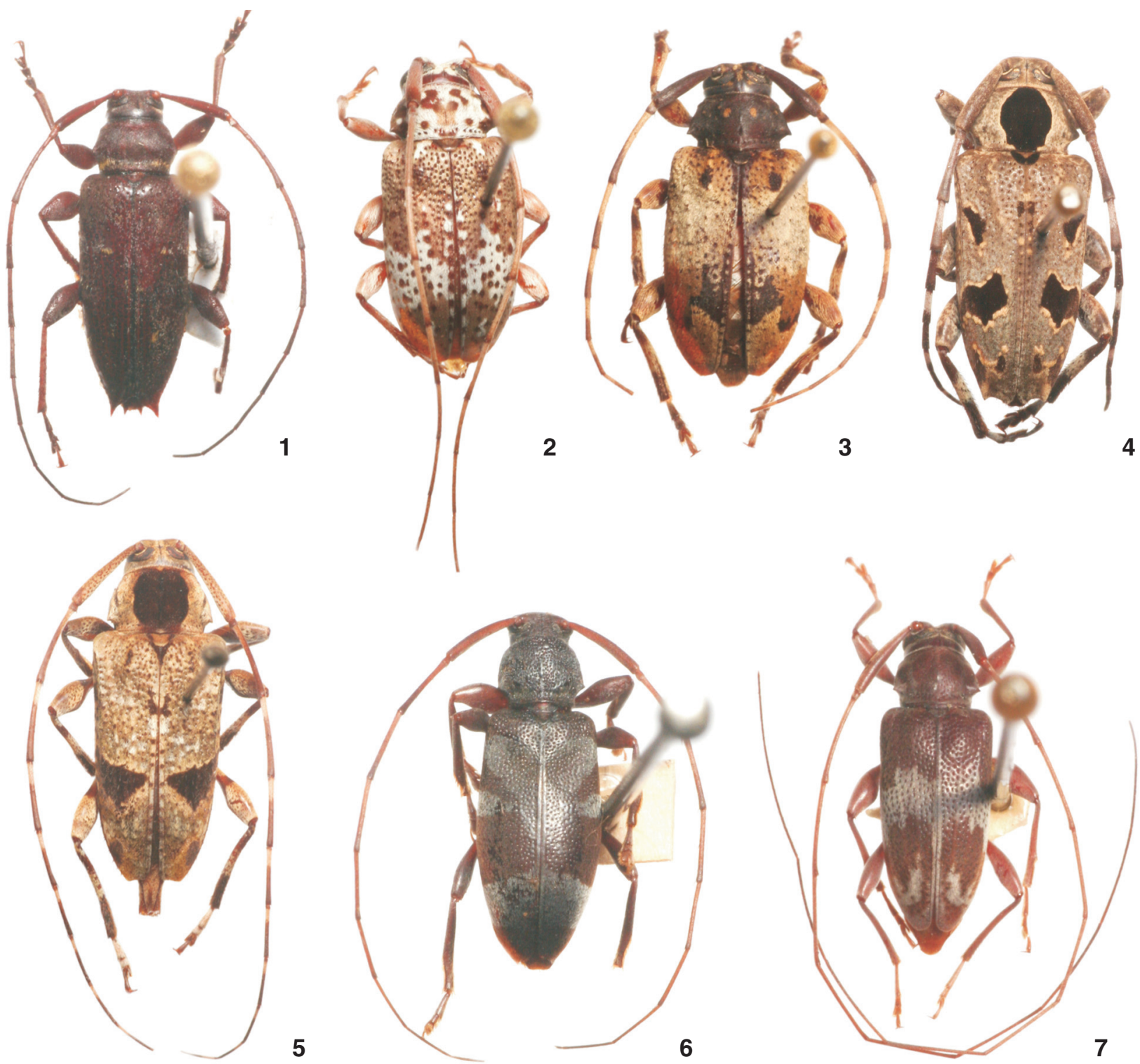

Figuras 1-7. (1) Alcidion inornatum sp. nov., holótipo fêmea, comprimento 8,7 mm; (2) Baryssinus giesberti sp. nov., holótipo macho, comprimento 9,0 mm; (3) Baryssinus mimus sp. nov., holótipo macho, comprimento 10,0 mm; (4) Carphina melanura sp. nov., holótipo fêmea, comprimento 12,0 mm; (5) Carphina sigillata parátipo fêmea, comprimento 12,0 mm; (6) Pseudolepturges caesius sp. nov., holótipo fêmea, comprimento 6,0 mm; (7) Lophopoenopsis albosparsus sp. nov., holótipo macho, comprimento 7,3 mm.

cinco manchas total ou parcialmente circundadas de estreita linha de pilosidade branco-amarelada, a primeira pequena, junto à sutura no fim do quarto basal, a segunda pequena, na mesma altura junto à carena lateral, a terceira grande, pós-mediana e oblíqua, de contorno irregular, eqüidistante da sutura e da margem e as duas últimas pequenas, anteapicais. Antenômeros IV, VI, VIII e X revestidos de pubescência branca, nos três quartos anteriores. Mesepisternos, metepisternos, lados do metasterno e fêmures revestidos de pubescência castanho-escura, entremeada com acinzentada. Tíbias castanho-escuras exceto faixa mediana esbranquiçada. Centro dos urosternitos I-V e lados do V subglabros, expondo o tegumento castanho-escuro.

Antenas apenas atingem os ápices dos élitros. Escapo ligeiramente mais longo que o antenômero III e este $1 / 3$ mais longo que o IV; V-XI distintamente decrescentes para a extremidade; XI cerca de $1 / 3$ do comprimento do III.

Lados do protórax com tubérculo pós-mediano, rombo. Pronoto sem elevações; pontuação grossa restrita à fileira junto

Revista Brasileira de Zoologia 24 (4): 1038-1042, dezembro 2007 
ao bordo posterior. Processo prosternal com a metade da largura da procoxa; processo mesosternal tão largo quanto a mesocoxa. Élitros com pontos grossos no terço basal e carena dorsal nitidamente demarcada nos dois terços anteriores; ápices transversalmente chanfrados, ângulos projetados em espinho obtuso.

Urotergito $\mathrm{V}$ com a margem apical subarredondada e urosternito $\mathrm{V}$, semicircularmente chanfrada.

Dimensões, em milímetros, fêmea. Comprimento total, 12,0/13,0; comprimento do protórax, 3,5/3,6; maior largura do protórax, 4,0/4,1; comprimento do élitro, 8,0/8,7; largura umeral, 5,0/5,2.

Material-tipo. Holótipo fêmea. BRASIL, Mato Grosso: Rio Verde, XI.1965, A. Maller leg. (MNRJ); parátipos: fêmea, mesmos dados do holótipo, XI.1964 (MNRJ); fêmea, XII. 1965 (MNRJ).

Discussão. O gênero Carphina Bates, 1872 apresenta oito espécies (Monné 2005) e destas, apenas Carphina sigillata Monné, 1985 (Fig. 5) apresenta uma grande mancha centro-mediana de pubescência preta no pronoto, assemelhando-se à pubescência do pronoto de C. melanura sp. nov. (Fig. 4). Esta espécie difere de $C$. sigillata pelo pronoto sem elevações, pelas antenas que apenas alcançam os ápices elitrais, com os antenômeros IV-XI distintamente decrescentes em comprimento e pelas extremidades elitrais com curto espinho no lado externo. Em $C$. sigillata, o pronoto apresenta tubérculo raso e centro-mediano, as antenas, nas fêmeas, ultrapassam os ápices elitrais no antenômero VII, os antenômeros IV-XI são gradualmente descrescentes em comprimento e os ápices dos élitros são obliquamente truncados, inermes no lado externo.

Etimologia. Grego, melanura = preto; referente à coloração da pubescência da mancha do pronoto.

\section{Lophopoenopsis Melzer, 1931}

Lophopoeum (Lophopoenopsis) Melzer, 1931: 63.

Lophopoenopsis; Gilmour, 1957: 10.

Espécie-tipo: Lophopoenopsis singulare Melzer, 1931, por designação original, registrada para o Brasil, do Espírito Santo ao Paraná.

O conjunto de caracteres mencionados a seguir permitem diferenciar Lophopoenopsis dos demais gêneros de Acanthocinini desprovidos de setas eretas na superfície dos élitros: antenas sem tufos de pêlos, protórax com tubérculo lateral, pronoto sem tubérculos elevados, processo mesosternal fortemente estreitado para trás, élitros sem carena lateral e metatarsômero I mais longo que II+III.

\section{Lophopoenopsis albosparsus sp. nov.} Fig. 7

Macho. Tegumento predominantemente castanho-escuro; tegumento castanho-avermelhado nas antenas, base dos fêmures, tíbias e tarsos. Pubescência de maneira geral acinzentada, esparsa e com brilho sedoso. Pubescência branco-acinzentada recobre, nos élitros, faixa transversal mediana de contornos irregulares e mancha anteapical em forma de "U". Escutelo recoberto por pubescência acinzentada densa.

Antenas muito longas, cerca de três vezes o comprimento do corpo, atingem a extremidade dos élitros no ápice do antenômero IV, o XI cerca de uma vez e meia o comprimento do X.

Lados do protórax com tubérculos pós-medianos aguçados no ápice. Pronoto com superfície irregular, sem tubérculos manifestos; pontuação fina e densa em toda a superfície. Processo prosternal muito estreito, aproximadamente $1 / 7$ da procoxa. Processo mesosternal distintamente estreitado para trás, largura cerca de 1/5 da mesocoxa. Élitros fina e densamente pontuados, principalmente na metade basal; extremidades arredondadas.

Urotergito e urosternito $\mathrm{V}$ transversalmente truncados na margem apical.

Dimensões, em milímetros, holótipo macho. Comprimento total, 7,3; comprimento do protórax, 1,5; maior largura do protórax, 1,7; comprimento do élitro, 5,2; largura umeral, 2,0.

Material-tipo. Holótipo macho. BrasIL, Bahia: Encruzilhada, Estrada Rio-Bahia km 965 (Motel da Divisa, 960 m), XI. 1974, Seabra \& Roppa leg. (MNRJ). Parátipos, dois machos, mesmos dados, XI.1970 (MNRJ); Itapetinga, macho, XI.1969, F.M. Oliveira leg. (MNRJ). Espírito Santo: Linhares, XII.1978, B. Silva leg. (MNRJ).

Discussão. Lophopoenopsis albosparsus sp. nov. (Fig. 7) separa-se de L. singulare Melzer, 1931 pelos lobos superiores dos olhos aproximados, distantes entre si 1/4 da largura de um lobo; em L. singulare os lobos são nitidamente separados, tão distantes entre si quanto a largura de um lobo; além disso, nesta espécie, os tarsômeros são recobertos por fina e densa pubescência cinza esbranquiçada, enquanto em L. albosparsus sp. nov. os tarsômeros têm pubescência rala, acastanhada.

Etimologia. Latim, albus = branco, sparsus = esparsa; referente à pubescência.

\section{Pseudolepturges Gilmour, 1957}

Pseudolepturges Gilmour, 1957: 26.

Espécie-tipo, Pseudolepturges rufulus (Bates, 1885) por designação original, mencionada para Guatemala.

Os caracteres que permitem distinguir Pseudolepturges dos gêneros de Acanthocinini neotropicais com os élitros desprovidos de setas eretas são: élitros sem crista centro-basal e sem carenas laterais, protórax com lados paralelos e tubérculo lateral situado no terço posterior, pronoto sem tubérculos, sulco da base do pronoto interrompido pela inserção dos tubérculos, antenas com 11 antenômeros e primeiro metatarsômero de comprimento mais longo que os dois seguintes reunidos.

\section{Pseudolepturges caesius sp. nov.}

Fig. 6

Fêmea. Tegumento predominantemente preto. Tegumento castanho-avermelhado nas antenas, pernas e face ventral. Pubescência de maneira geral castanho-escura. Pubescência azulacinzentada disposta em manchas nos élitros: a primeira arredondada, pós-escutelar, junto à sutura; a segunda na metade 
basal, transversa, da sutura à margem; a terceira pequena e arredondada, no meio da sutura, apenas separada de faixa transversal que alcança a margem e a última reveste o terço apical sem alcançar as extremidades. Protórax, nos lados, revestido de fina pubescência acinzentada.

Cabeça fina e densamente pontuada no occipício. Antenas alcançam as extremidades dos élitros no meio do antenômero VII; extremidade distal dos antenômeros com escassas setas eretas.

Protórax com os lados subparalelos nos 2/3 anteriores; tubérculos laterais pequenos e aguçados, situados no início do terço posterior. Pronoto sem tubérculos, muito densamente pontuado. Élitros com os ápices transversalmente chanfrados, os ângulos projetados em espinho obtuso, o externo mais desenvolvido que o sutural.

Urotergito V com a margem apical truncada; urosternito $\mathrm{V}$ com a margem apical chanfrada e ângulos com curto espinho.

Macho. Antenas alcançam os ápices dos élitros na extremidade distal do antenômero VI; urotergito e urosternito V com as margens apicais truncadas.

Dimensões, em milímetros, macho/fêmea. Comprimento total, 5,0/6,0; comprimento do protórax, 0,9/1,1; maior largura do protórax, 1,5/1,5; comprimento do élitro, 3,5/4,4; largura umeral, $1,8 / 1,8$.

Material-tipo, holótipo fêmea, BRASIL, Rondônia: Ouro Preto do Oeste, X.1983, O. Roppa, J. Becker \& B. Silva leg. (MNRJ); parátipo fêmea, mesmos dados do holótipo (MNRJ); parátipo macho, 62 km SW Ariquemes (Rancho Grande), 10.XI.1994,
O’Brien leg. (ACMT); parátipo macho, Pará: Tucuruí, I.1980, B. Silva leg. (MNRJ).

Discussão. Pseudolepturges caesius sp. nov. (Fig. 6) difere de $P$. rufulus (Bates, 1885) pelo desenho e coloração elitral com manchas de pubescência azul-acinzentada e pelo pronoto muito fina e densamente pontuado. Em P. rufulus (Bates 1885: 406, pr. 24, fig. 26) os élitros são amarelados, com máculas cinzentoesbranquiçadas e o pronoto não apresenta pontuação densa.

Etimologia. Latim, caesius = azul-acinzentado; referente à coloração da pubescência nos élitros.

\section{AGRADECIMENTOS}

A. José R.M. Mermudes (Universidade do Estado do Rio de Janeiro) pela execução das fotos e a James Wappes (ACMT) pelo envio de material.

\section{REFERÊNCIAS BIBLIOGRÁFICAS}

Bates, H.W. 1885. Biologia Centrali-Americana, Insecta, Coleoptera, suppl. to Longicornia. London, 5: 249-436.

Gilmour, E.F. 1957. On the Neotropical Acanthocinini (Coleoptera, Cerambycidae, Lamiinae). Some new genera and species. Arquivos de Biologia e Tecnologia 10 (1): 3-36.

Melzer, J. 1931. Longicórneos americanos, principalmente do Brasil, novos ou pouco conhecidos (Coleoptera, Cerambycidae). Archivos do Instituto Biologico 4: 51-82.

Monné, M.A. 2005. Catalogue of the Cerambycidae (Coleoptera) of the Neotropical Region. Part II. Subfamily Lamiinae. Zootaxa 1023: 1-759.

Recebido em 09.V.2007; aceito em 20.XI.2007. 